\title{
LA NUEVA CONCEPCIÓN CONSTITUCIONAL DE LA UNIDAD DE MERCADO. LOS MECANISMOS DE GARANTÍA Y PROMOCIÓN DEL MERCADO NACIONAL ÚNICO EN LA RECIENTE JURISPRUDENCIA CONSTITUCIONAL
}

The new constitutional conception of the market unity. The mechanisms of safeguard and promotion of the unique national market in the recent Constitutional Jurisprudence

\author{
TOMÁS DE LA QUADRA-SALCEDO JANINI \\ Universidad Autónoma de Madrid \\ tomas.quadra@uam.es
}

Cómo citar/Citation

De la Quadra-Salcedo Janini, T. (2018).

La nueva concepción constitucional de la unidad de mercado.

Los mecanismos de garantía y promoción del mercado nacional único en la reciente jurisprudencia constitucional.

Revista Española de Derecho Constitucional, 114, 271-299. doi: https://doi.org/10.18042/cepc/redc1l4.09

\section{Resumen}

El Tribunal Constitucional ha realizado en los últimos tiempos una relectura de diversos preceptos y principios integrantes de lo que se ha denominado doctrinalmente la "Constitución económica». En las recientes SSTC 79/2017, 110/2017 y 111/2017 el Tribunal Constitucional acoge una construcción doctrinal que supone reconocer que el grado de unidad —o de fragmentación- del mercado nacional depende en buena medida, y en cada momento, de una decisión política de las Cortes Generales sin que el mismo se encuentre impuesto directamente por la Constitución. 


\title{
Palabras clave
}

Constitución económica; unidad de mercado; garantías estructurales y garantías dinámicas del mercado nacional único; jurisprudencia constitucional; STC $79 / 2017$.

\begin{abstract}
The Constitutional Court has made in recent times a reinterpretation of various precepts and principles of what has been denominated doctrinally the economic Constitution. In the recent Judgments 79/2017, 110/2017 and 111/2017 the Constitutional Court welcomes a doctrinal construction that implies that the degree of unity - or fragmentation — of the national market depends to a large extent, and at every moment, on a political decision of the national Parliament without it being directly imposed by the Constitution.
\end{abstract}

\section{Keywords}

Economic constitution; market unity; structural guarantees and dynamic guarantees of the single national market; constitutional jurisprudence; Constitutional Court Judgment 79/2017. 


\section{SUMARIO}

I. INTRODUCCIÓN. II. UNA NUEVA INTERPRETACIÓN DEL MERCADO NACIONAL ÚNICO. III. ¿̇UNA INTERPRETACIÓN PREVIAMENTE ANUNCIADA?: 1. La evolución de la interpretación del alcance de las denominadas garantías estructurales del mercado único: 1.1. El alcance de las reglas recogidas en el art. 139 CE. 1.2. La libertad de empresa del art. 38 CE tampoco es una garantía de la igualdad en las condiciones básicas de ejercicio de la actividad económica en todo el territorio nacional. 1.3. La competencia recogida en el art. 149.1.1 CE no es, por sí misma, un límite al ejercicio competencial autonómico. 2. El alcance de las denominadas garantías dinámicas del mercado único. IV. A MODO DE CONCLUSIÓN. BIBLIOGRAFía.

\section{INTRODUCCIÓN}

El Tribunal Constitucional ha realizado en los últimos tiempos una relectura de diversos preceptos y principios integrantes de lo que se ha denominado doctrinalmente la "Constitución económica»" Así, el máximo intérprete de la norma fundamental ha perfilado algunos de aquellos principios que fundan nuestro modelo económico constitucional; tanto del sustantivo, al reinterpretar aspectos del significado y alcance de la libertad de empresa recogida en el art. $38 \mathrm{CE}^{2}$, como del territorial, al esclarecer el significado de

1 La Constitución económica ha sido definida por el propio Tribunal Constitucional como aquel conjunto de normas destinadas a proporcionar el marco jurídico fundamental para la estructura y funcionamiento de la actividad económica, resaltando la importancia que, especialmente en Estados como el nuestro, de estructura territorial compuesta, adquiere la exigencia de que los principios básicos del orden económico sean unos y los mismos en todo el ámbito nacional (STC 64/1990, de 5 de abril, FJ 2).

2 El Tribunal Constitucional ha asumido explícitamente el empleo de un canon menos incisivo que el de proporcionalidad a la hora de controlar la constitucionalidad de determinados actos y disposiciones de los poderes públicos que restringen la libertad de empresa desde la STC 53/2014, de 10 de abril, donde afirma que «la libertad de empresa reconocida en el art. $38 \mathrm{CE}$ exige que las regulaciones públicas que afectan al ejercicio de una actividad empresarial, sin afectar al propio acceso a la misma, sean constitucionalmente adecuadas» (FJ 7). La referida doctrina se ha consolidado en numerosas sentencias posteriores [SSTC 30/2016, de 18 de febrero, FJ 6, 35/2016, de 3 de marzo, FJ 4; 89/2017, de 4 de julio, FJ 14; 111/2017, de 5 de octubre, FJ 4 a); y 7/2018, de 25 de enero FJ 7 a)]. Ello supone acercar la doctrina en materia de 
la unidad de mercado y reinterpretar aquellos preceptos directamente vinculados con su garantía y promoción como es, por ejemplo, el que se refiere a la libre circulación de personas y bienes recogido en el art. 139.2 CE.

En las páginas que siguen abordaremos fundamentalmente el examen de aquellos aspectos que se refieren a la Constitución económica territorial y a la reinterpretación por la jurisprudencia constitucional de los mecanismos de garantía y promoción de la unidad de mercado.

En relación con ello, deben destacarse las recientes SSTC 79/2017, 110/2017 y 111/2017, en las que el Tribunal Constitucional acoge una construcción doctrinal que supone reconocer que el grado de unidad - o de fragmentación - del mercado nacional depende en buena medida, y en cada momento, de una decisión política de las Cortes Generales sin que el mismo se encuentre impuesto directamente por la norma fundamental.

\section{UNA NUEVA INTERPRETACIÓN DEL MERCADO NACIONAL ÚNICO}

La STC 79/2017, de 22 de junio, al hilo de resolver el recurso de inconstitucionalidad interpuesto por el Parlamento de Cataluña contra diversos preceptos de la Ley 20/2013, de 9 de diciembre, de Garantía de la Unidad de Mercado $^{3}$ ha realizado en su FJ 2 una novedosa interpretación de la norma fundamental en lo que se refiere a los mecanismos previstos en ella para garantizar y promover el mercado único. La referida sentencia ha sido la primera de una serie, pues la norma estatal fue impugnada por diversas comunidades autónomas ${ }^{4}$.

derechos económicos a la doctrina existente en otros Estados como el norteamericano o el alemán. Quadra-Salcedo Janini (2004).

3 Sobre la Ley 20/2013 se ha publicado una ingente y excelente doctrina crítica entre la que cabe destacar: Alonso Más (2014); Fernández Farreres (2014); Muños Machado (2014); Rebollo Puig (2014); Carlón Ruiz (2014); Cidoncha Martín (2015); Narbón Fernández (2016); Urrutia Libarona (2016); Padros Reig y Macias Castaño (2014).

4 A la STC 79/2017 le han seguido las SSTC 110/2017, 111/2017 y 119/2017. Las SSTC 110/2017 y 111/2017 acogen explícitamente la doctrina fijada en el STC $79 / 2017$ al afirmar «dar [...] por reproducidos los fundamentos jurídicos 2 y 11 que aquella Sentencia dedica al examen del propósito de la Ley 20/2013, a recordar la doctrina de este Tribunal en relación con la unidad de mercado y los mecanismos que nuestra Constitución dispone para su eventual promoción (FJ 2), al encuadramiento de la controversia competencial (FFJJ 4 y 5), al examen de las respuestas dadas a la pluralidad regulatoria (FJ 12) y al alcance del principio de territorialidad de las competencias (FJ 13)». 
La STC 79/2017 parte de la caracterización tradicional que ha venido realizando la doctrina jurisprudencial de un mercado único: 1) ser un espacio donde se encuentran garantizadas la libre circulación de personas y bienes ${ }^{5}$, y 2) ser un espacio donde las condiciones esenciales de ejercicio de la actividad económica son iguales ${ }^{6}$.

Sin embargo, es al examinar los mecanismos constitucionales de garantía y promoción de tales rasgos donde encontramos la novedad doctrinal. En efecto, de la STC 79/2017 se deriva que para el Tribunal Constitucional los rasgos del mercado único no se encontrarían directamente impuestos y garantizados por la propia Constitución, sino que esta habría previsto mecanismos para promover aquellos, pero son mecanismos cuya activación depende, en buena medida, de la voluntad política de los órganos normativos del Estado7.

Así, la STC 79/2017 diferencia entre lo que denomina las "garantías estructurales» y lo que denomina las "garantías dinámicas» del mercado único.

Las primeras, las estructurales, serían aquellas que suponen un límite en sí - un límite directo desde la Constitución — a la diversidad regulatoria que pueden introducir los legisladores autonómicos, y entre las que se encontrarían, tal como enumera la propia STC 79/2017, a) la reserva competencial al Estado de ámbitos materiales concretos de manera exclusiva y excluyente entre otros, cita el Tribunal, los recogidos, por ejemplo, en los apdos. 6 (legislación mercantil, penal y procesal), 7 (legislación laboral), 8 (legislación civil) o 9 (legislación sobre propiedad intelectual e industrial) del art. 149.1 CE-; b) la obligación de respetar el contenido esencial de derechos fundamentales que permite establecer un sustrato de igualdad que deriva directamente de la propia Constitución y que queda reforzado en cuanto a los regulados en la sección primera del capítulo II de dicho título I por el hecho de que su

5 La garantía de la libre circulación de personas y bienes supondría que las personas, bienes, servicios y capitales puedan circular con libertad por todo el territorio español. Albertí Rovira (1995: 256)

6 La garantía de la igualdad de condiciones de ejercicio de la actividad económica supondría que los operadores económicos se deben encontrar en una posición jurídica sustancialmente uniforme en todo el espacio económico sobre el que se proyecta el mercado único. No pueden darse igualdad de condiciones competitivas en el interior de un mercado si no hay una igualdad sustancial en el contenido del derecho «ordenador» del mismo, y para ello es necesaria la eliminación de aquellas disparidades jurídicas que, originadas por la vigencia territorial de los ordenamientos jurídicos autonómicos, falseen las condiciones de competencia en el interior del mercado. Así lo señala Marx (1976: 139 y ss) para el caso del mercado comunitario.

7 En este sentido, Quadra-Salcedo Janini (2008). 
desarrollo está reservado a Ley Orgánica (art. 81.1 CE); o c) el establecimiento en la Constitución de una serie de principios que limitan y enmarcan la acción de todos los poderes públicos en el ejercicio de sus competencias (por ejemplo, aquellos principios recogidos en el art. $139 \mathrm{CE}$, cuyo alcance, en lo que se refiere por ejemplo al apdo. 2, ha sido igualmente reinterpretado en las recientes SSTC 111/2017, de 5 de octubre, y 7/2018, de 25 de enero, y que serán igualmente objeto de análisis en estas páginas).

Las segundas, las garantías dinámicas del mercado único, estarían constituidas por los títulos competenciales horizontales reservados al Estado fundamentalmente en los apdos. 1 (sobre regulación de la condiciones básicas que garantizan la igualdad de todos los españoles en el ejercicio de los derechos y en el cumplimiento de los deberes) y 13 (sobre bases y coordinación de la planificación general de la actividad económica) del art. 149.1 CE, y que permitirían a este intervenir normativamente cuando las garantías estructurales —aquellas que suponen un límite en sí, un límite directo desde la Constitución, a la diversidad regulatoria que puedan introducir los legisladores autonómicos-se demuestran insuficientes para imponer los rasgos del mercadoúnico.

Así, la STC 79/2017 afirma que «a través del ejercicio efectivo de las competencias contenidas en los referidos títulos horizontales, el Estado promueve, en su caso, aquellos rasgos que de acuerdo con la doctrina de este Tribunal caracterizan el mercado único» ${ }^{8}$; asumiendo, por tanto, que en último término corresponde al Estado la decisión política de ejercer o no ejercer sus competencias transversales para promover los rasgos del mercado único, pues debe recordarse que tales competencias no suponen, en realidad, una reserva al Estado de ámbitos materiales exclusivos y excluyentes, sino que suponen habilitaciones a aquel para la consecución de determinados fines ${ }^{9}$, incluso

8 Las cursivas son nuestras.

9 En relación con la competencia atribuida al Estado en el artículo 149.1.1 CE sobre la regulación de las condiciones básicas que garantizan la igualdad de los españoles en el ejercicio de los derechos y deberes constitucionales, la doctrina constitucional como se examina supra ha reiteradamente negado "el carácter de límite directo al artículo 149.1.1 CE, pues este Tribunal ha considerado que tal precepto no reserva al Estado un ámbito material o sustantivo susceptible de ser vulnerado, sino, simplemente, establece una habilitación formal para que el Estado condicione - mediante, precisamente, el establecimiento de unas 'condiciones básicas' uniformes - el ejercicio de esas competencias autonómicas con el objeto de garantizar la igualdad de todos los espańoles en el ejercicio de sus derechos y en el cumplimiento de sus deberes constitucionales" [SSTC 89/2017, de 4 de julio, FJ 6 b), 111/2017, de 5 de octubre, FJ 5 b), y 7/2018, de 25 de enero, FJ 6]. 
aunque ello suponga, caso de efectivamente ejercerse, afectar a ámbitos materiales reservados de manera exclusiva a las CC. AA.

La razón de negar que la Constitución imponga/garantice directamente los rasgos del mercado único no es otra que considerar que ello sería incompatible con la idea misma de un Estado descentralizado, pues para el Tribunal Constitucional sería frontalmente contradictorio con la autonomía constitucionalmente garantizada imponer, también desde la Constitución, una igualdad, aun básica, en las condiciones de ejercicio de la actividad económica en todo el territorio del Estado.

Así, aquellos obstáculos y trabas a la actividad económica que se derivan de lo que el preámbulo de la norma impugnada, la Ley 20/2013 de Garantía de la Unidad de Mercado, denomina «la fragmentación del mercado nacional» —y que subsisten, por ser un ejercicio competencialmente legítimo, a la aplicación de aquellas disposiciones constitucionales que proscriben directamente la diversidad (las denominadas garantías estructurales) - pueden en nuestro ordenamiento constitucional ser atenuados, de acuerdo con la nueva doctrina del Tribunal, a través del ejercicio efectivo por parte del Estado de sus competencias horizontales (las denominadas garantías dinámicas).

La doctrina recogida en la STC 79/2017 supone reconocer que el grado de unidad o de fragmentación del mercado nacional depende en cada momento de una decisión política de las Cortes Generales, lo que implica que la determinación de cuanta unidad (o de cuanta descentralización) es necesaria en el mercado español no es una determinación jurídica sino política que nuestra Constitución, al atribuir al Estado competencias horizontales, ha considerado que debe corresponder realizaren cada momento a los representantes de todos los ciudadanos.

La capacidad normativa que nuestro sistema competencial constitucional reconoce a las CC. AA. determina la posibilidad de que se produzca una pluralidad normativa que suponga una fragmentación de aquellas normas que rigen el mercado nacional, tal consecuencia — superados determinados límites a la diversidad — no es en sí misma inconstitucional, pero es el presupuesto para que, en su caso, el Estado decida a través del libre ejercicio de sus competencias horizontales atenuar tal pluralidad. La Constitución no blinda por tanto y ex ante los rasgos de un mercado nacional único, pero prevé instrumentos que permiten, decisión política del Estado mediante, su mayor o menor consecución.

La referida concepción supone un cambio doctrinal de cierto calado, pues la doctrina tradicional del Tribunal había venido afirmando hasta ese momento que era la Constitución misma la que directamente garantizaba los rasgos de un mercado nacional único. 


\section{III. ¿̇UNA INTERPRETACIÓN PREVIAMENTE ANUNCIADA?}

Hasta la adopción de la STC 79/2017, un amplio sector de la doctrina tanto académica como jurisprudencial ha venido considerando que el principio de unidad de mercado implicaría que ningún poder público puede adoptar disposiciones que supongan el troceamiento o fragmentación del mercado nacional, la creación de mercados separados ${ }^{10}$. De ello se derivaba la afirmación de que nuestra Constitución impone directamente un mercado nacional único caracterizado por los dos rasgos ya señalados: ser un espacio donde se encuentran garantizadas la libre circulación de personas y bienes, y ser un espacio donde las condiciones esenciales de ejercicio de la actividad económica son iguales.

Sin embargo, si se examina la propia evolución previa de la doctrina del Tribunal es posible constatar cómo tal afirmación había ido perdiendo los diversos anclajes en los que se había venido justificando incluso antes de que el propio Tribunal adoptase la STC 79/2017.

En efecto, la afirmación de que la Constitución garantiza directamente un mercado nacional único se había venido sustentando en la interpretación de una diversidad de preceptos constitucionales que, sin embargo, a lo largo del tiempo habían venido siendo sometidos a una reinterpretación que habría hecho perder a aquella afirmación su justificación.

Ciertamente, la unidad de mercado no está formulada expresamente en la Constitución; sin embargo el principio de unidad de mercado se habría derivado doctrinalmente del propio art. 2 de la Constitución, que proclama "la indisoluble unidad de la Nación española».

No obstante lo anterior, buena parte de la doctrina ha subrayado que el principio de unidad de mercado carecería de fuerza por sí solo como parámetro de validez, lo que haría necesario acudir a aquellos concretos preceptos constitucionales que en desarrollo de aquel principio general aspiran a establecer garantías para su consecución ${ }^{11}$.

En esta línea, para la doctrina tradicional del Tribunal Constitucional, una de las manifestaciones de la unidad básica que la Constitución proclama «se concreta en la "unidad de mercado" o en la unidad del orden económico

10 Cosculluela Montaner (2003: 133), para quien tanto del art. 38 CE como del art. 139.2 CE se deduce la unidad del mercado español.

11 Para Albertí Rovira (1995: 253 y ss.) no puede producirse una vulneración de la unidad de mercado que no constituya una violación de alguno de los preceptos que sirven a tal objetivo o en los que se concreta esta exigencia constitucional; en igual sentido Carrasco Durán (2005) y Cidoncha Martín (2015: 110). 
en todo el ámbito del Estado, como se deduce tanto del Preámbulo — que garantiza la existencia de un "orden económico y social justo"- como de una interpretación conjunta de los arts. 2, 38, 40.1, 130.1, 131.1, 138.1 y 2, 139.2, 149.1.1 y 157.2 CE» ${ }^{12}$. Para el Tribunal es posible inferir de esa unidad, tal como él ha hecho reiteradamente, «la exigencia de un mercado único [...] configurándola como un límite de las competencias autonómicas [...] término éste, el de "mercado", que equivale a "mercado nacional" o "mercado espańol", esto es, al espacio económico unitario»"

Así, para el Alto Tribunal

la efectiva unicidad del orden económico nacional requiere la unidad de mercado en la medida en que están presentes dos supuestos irreductibles: la libre circulación de bienes y personas por todo el territorio nacional, que ninguna autoridad puede obstaculizar directa o indirectamente (art. 139.2 CE), y la igualdad de las condiciones básicas de ejercicio de la actividad económica (arts. 139.1 y 149.1.1 CE), sin los cuales no es posible alcanzar en el mercado nacional el grado de integración que su carácter unitario impone ${ }^{14}$.

En este sentido, la unidad de mercado vendría, en último término asegurada a través de la previsión en la Constitución de una serie de preceptos - lo que en la terminología de la STC 79/2017 se denominan garantías estructurales - que limitan y enmarcan la acción de todos los poderes públicos, y especialmente de los autonómicos, en el ejercicio de sus competencias.

\section{LA EVOLUCIÓN DE LA INTERPRETACIÓN DEL ALCANCE DE LAS DENOMINADAS GARANTÍAS ESTRUCTURALES DEL MERCADO ÚNICO}

En las páginas que siguen examinaremos cómo con carácter previo a la explicitación en la STC 79/2017 de una nueva doctrina en relación con la unidad de mercado, el propio Tribunal Constitucional habría venido diluyendo la interpretación del alcance mismo de aquellos preceptos constitucionales

12 Unidad que supondría que en Estados como el nuestro, de estructura territorial compleja, la exigencia de que los principios básicos del orden económico sean unos y los mismos en todo el ámbito nacional es una proyección concreta del más general principio de unidad que el art. 2 CE consagra (SSTC 1/1982, de 28 de enero, FJ 1; 11/1984, de 2 de febrero, FJ 5; y 24/1986, de 14 de febrero. FJ 4).

13 STC 96/2002, de 25 de abril, FJ 11.

14 STC 96/2002, FJ 11. 
que doctrinal y jurisprudencialmente se habían venido interpretado como límites a la acción de las CC. AA. y consiguientemente como instrumentos de garantía directa de los rasgos del mercado nacional único. Analizaremos, así, el alcance de aquellos preceptos constitucionales que han sido interpretados en algún momento por la doctrina científica y por la jurisprudencia constitucional como preceptos garantizadores de la igualdad en las condiciones esenciales de ejercicio de la actividad económica en todo el territorio nacional. Se trata de los dos apartados del art. 139 CE, del art 38 CE y del art. 149.1.1 CE.

\subsection{El alcance de las reglas recogidas en el art. 139 CE}

La jurisprudencia constitucional ha afirmado, refiriéndose a los dos apartados apdos. del art. $139 \mathrm{CE}$, que este tipo de preceptos «son presupuestos o límites, pero no títulos competenciales $»^{15}$. Para el Tribunal Constitucional los principios consagrados en el art. 139 CE constituirían límites y directrices que acotan y guían el ejercicio de las competencias que posee el Estado ex art. 149 C.E. y las CC. AA. en virtud de sus respectivos estatutos ${ }^{16}$. Por tanto, el art. 139 CE no sustrae competencias sobre una materia determinada a los poderes públicos sino que condiciona el ejercicio de las competencias atribuidas ${ }^{17}$.

Así, nuestra Constitución habría impuesto un «límite insuperable a la variedad jurídica deducida del pluralismo territorial» a través del sometimiento del ejercicio de las competencias de los poderes públicos a los dos apartados del art. 139 CE (Solozábal Echavarría, 1998: 119). La cuestión que se plantea es cuál es el concreto alcance de tales límites a la variedad jurídica y sobre todo si tal alcance es suficiente para garantizar los rasgos de un mercado único.

15 STC 61/1997, de 20 de marzo, FJ 7. Frente a ello, para Cosculluela Montaner (2003: 133) el art. 139.2 parece que sería un precepto atributivo de competencias al Estado, pues recogería en nuestro ordenamiento el equivalente de la cláusula de comercio incluida en la Constitución norteamericana que determina la competencia federal sobre el comercio. Sin embargo, de la jurisprudencia constitucional se deriva que, frente a lo sostenido por Cosculluela, el art. 139.2 constitucionalizaría la cláusula de comercio norteamericana en su perspectiva negativa o durmiente, como precepto limitador del ejercicio de las competencias, pero no en su perspectiva positiva, como precepto atributivo de competencias al Estado. Sobre la diferencia entre la cláusula de Comercio negativa o durmiente y la cláusula de comercio positiva véase Quadra-Salcedo Janini (2004: 65 y ss.).

16 STC 173/1998, de 23 de julio.

17 En este sentido, Cabellos Espierrez (2001: 40-41). 


\subsubsection{El sentido del art. 139.1 CE: la garantía de la igualdad de derechos de los españoles ante cada ordenamiento individualmente considerado}

El apdo. 1 del art. 139 CE dispone que «todos los españoles tienen los mismos derechos y obligaciones en cualquier parte del territorio nacional».

El precepto supone que no únicamente los derechos y deberes constitucionales, sino cualquier derecho u obligación que se establezca en el ordenamiento jurídico, se encuentra afectado por la referida disposición.

El Tribunal Constitucional, ya en su primera jurisprudencia, señaló que el principio recogido en el apdo. 1 del art. $139 \mathrm{CE}$ «no puede ser entendido en modo alguno como [la imposición de] una rigurosa y monolítica uniformidad del ordenamiento de la que resulte que, en igualdad de circunstancias, en cualquier parte del territorio nacional, se tienen los mismos derechos y obligaciones». Y no puede ser así entendido porque «la potestad legislativa de que las CCAA gozan da potencialmente a nuestro ordenamiento una estructura compuesta, por obra de la cual puede ser distinta la posición jurídica de los ciudadanos en las distintas partes del territorio nacional ${ }^{18}$.

Así, en efecto, es inherente a nuestro sistema constitucional que, como consecuencia del ejercicio por las CC. AA. de sus competencias exclusivas o de desarrollo legislativo, los ciudadanos residentes en los distintos territorios autonómicos puedan estar sometidos a regímenes jurídicos diferenciados en las áreas materiales correspondientes a dichas competencias y, consecuentemente, tengan diferentes derechos en esas áreas ${ }^{19}$.

Una buena parte de la doctrina académica ha interpretado, entonces, el apdo. 1 del art. 139 CE como un mandato de igualdad de todos los españoles «ante cada ordenamiento autonómico» en el sentido de imponer una prohibición de discriminación de los ciudadanos por las CC. AA. por razón de

18 STC 37/1981, FJ 2. Ello no fue óbice para que en relación con los derechos constitucionales la misma sentencia afirmase que esta diversidad se da dentro de la unidad y que, por consiguiente, la potestad legislativa de las comunidades autónomas no puede regular las condiciones básicas de ejercicio de los derechos o posiciones jurídicas fundamentales que quedan reservadas a la legislación del Estado (arts. 53 y 149.1.1 CE). Construcción en relación con el art. 149.1.1 CE que será revocada por el Tribunal Constitucional en los años noventa, como se desarrolla supra.

19 STC 247/2007, de 12 de diciembre, FJ 13 b). En esta línea ya había señalado De Otto (1986: 145-146) que el art. 139.1 de la CE no puede contener un mandato de absoluta uniformidad en los derechos y obligaciones por la muy obvia razón de que tal cosa es contradictoria con la pluralidad de ordenamientos jurídicos que se derivan de la estructura autonómica del Estado. 
factores de conexión territorial (De Otto, 1986: 153 y ss.; Aja, 1992: 33-34; Albertí Rovira, 1995: 224; 2008: 2093 y ss.; Ruiz-Rico Ruiz, 2001: 138 y ss.; Cámara Villar, 2007: 27; Quadra-Salcedo Janini, 2008: 33 y ss.). Esta interpretación del apdo. 1 del art. 139 CE cabría vincularla con el sentido que tuvo el art. 17 de la Constitución de 1931 cuando establecía que «en las regiones autónomas no se podrá regular ninguna materia con diferencia de trato entre naturales del país y los demás españoles». Así, en línea con lo establecido en la Constitución de 1931, se impondría una lectura del apdo. 1 del art. 139 CE, anteponiendo el final de la frase al comienzo de la misma y entendiendo que «en cualquier parte del territorio nacional [...] todos los espańoles tienen los mismos derechos y obligaciones». El precepto no proscribiría la diversificación de las posiciones jurídicas de los ciudadanos según el ordenamiento autonómico a que estén sujetos, sino que ordenaría que, en principio, dentro de cada uno de esos ordenamientos se trate igual a todos los españoles ${ }^{20}$.

Es en buena medida esta interpretación la que acoge la STC 79/2017 cuando afirma que

la autonomía significa precisamente la capacidad de cada nacionalidad o región para decidir cuándo y cómo ejercer sus propias competencias, en el marco de la Constitución y del Estatuto. Y si, como es lógico, de dicho ejercicio derivan desigualdades en la posición jurídica de los ciudadanos residentes en cada una de las distintas Comunidades Autónomas, no por ello resultan necesariamente infringidos los arts. 1, 9.2, 14, 31.1, 38, 139, 149.1.1 y 149.1.13 de la Constitución, ya que estos preceptos no exigen un tratamiento jurídico uniforme de los derechos y deberes de los ciudadanos en todo tipo de materias y en todo el territorio del Estado, lo que sería frontalmente incompatible con la autonomía ${ }^{21}$.

20 La exigencia de uniformidad de trato dentro de cada ordenamiento autonómico significaría, por tanto, la prohibición de que se trate, en cada comunidad autónoma, de forma discriminatoria a vecinos o naturales de otras comunidades. Señala López Guerra (1990: 83) que el art. 139.1 ha de interpretarse teniendo en cuenta la diversidad que supone el hecho autonómico, lo que supone que tal artículo no significa la uniformidad de situaciones jurídicas en toda España, sino la uniformidad de trato de cada ordenamiento autonómico. Ello significa, por tanto, la prohibición de que se trate, en cada comunidad utónoma y en aplicación de su ordenamiento, de forma discriminatoria, a vecinos o «naturales» de cada comunidad, con respecto a vecinos o «naturales» de otra. El reconocimiento constitucional de la igualdad de trato debería suponer la inconstitucionalidad de todas aquellas regulaciones autonómicas y locales que establecen diferencias en el acceso a los servicios, bienes y prestaciones públicas en función del tiempo de residencia efectiva. Quadra-Salcedo Janini (2009: 135 y ss.).

STC 79/2017, de 22 de junio, FJ 2 a). 
Ciertamente, el Tribunal Constitucional no ha mantenido siempre la referida interpretación que estando presente ya en la jurisprudencia original, STC 37/1981, parece haber sido acogida ahora en la más reciente, STC 79/2017. En efecto, el Tribunal Constitucional en la STC 52/1988, FJ 3, caracterizó el principio establecido en el apdo. 1 del art. 139 CE como aquel que garantiza "la igualdad sustancial de la situación jurídica de los españoles en cuanto tales, en todo el territorio nacional $\aleph^{22}$. En la misma línea, la STC 247/2007, afirmó, en relación en esta ocasión con los derechos constitucionales, que si bien el art. 139.1 CE no contempla una uniformidad absoluta del régimen de los derechos constitucionales en todo el territorio nacional, sí contempla un principio de igualdad sustancial susceptible de modulaciones diferenciadas en mayor o menor grado en las CC. AA., según el tipo de derecho de que se trate y el reparto competencial en la materia implicada ${ }^{23}$.

Sin embargo, la propia STC 247/2007 pareció radicar al mismo tiempo tal principio de igualdad sustancial de los derechos constitucionales en el hecho de que se trata de derechos que «no sólo se imponen al legislador, sino que son resistentes al mismo, de manera que si aquél legislara contra dicho contenido esencial, el producto - la ley — podrá ser declarado inconstitucional», es decir, la igualdad sustancial radicaría más bien en lo dispuesto en el art. $53 \mathrm{CE}$, en relación con el contenido esencial como límite indisponible para cualquier legislador, que en lo dispuesto en el art. 139.1 CE.

Así, para la STC 247/2007, es la garantía de un contenido esencial la que produce que puede hablarse, por tanto, de un sustrato de igualdad en todo el territorio nacional respecto de los derechos recogidos en el título I, capítulo II de la Constitución. Sustrato de igualdad que «deriva directamente de la propia Constitución y que queda reforzado en cuanto a los regulados en la sección primera del capítulo II de dicho título I por el hecho de que su desarrollo está reservado a Ley Orgánica (art. 81.1 CE)».

Idea que se encuentra recogida en la STC 79/2017 cuando dispone que la unidad del mercado nacional se encuentra directamente promovida: [...] b) a través del respeto del contenido esencial de derechos fundamentales, pues "puede hablarse [...] de un sustrato de igualdad en todo el territorio nacional respecto de estos derechos, sustrato de igualdad que deriva directamente de la propia Constitución y que queda reforzado en cuanto a los regulados en la

22 Interpretación que ha sido igualmente sostenida doctrinalmente por Aragón Reyes (2008: XIV) y Cidoncha Martín (2015: 111), que consideran que el art. 139.1 CE impone no solo la igualdad de derechos en el ámbito intrautonómico, sino también en el ámbito interautonómico.

23 STC 247/2007, de 12 de diciembre, FJ 13 a). 
sección primera del capítulo II de dicho título I por el hecho de que su desarrollo está reservado a Ley Orgánica (art. 81.1 CE) (STC 247/2007, FJ 13)».

\subsubsection{El sentido del art. 139.2: la proscripción del proteccionismos económico}

El apdo. 2 del art. 139 CE prohíbe a cualquier «autoridad» la adopción de «medidas que directa o indirectamente obstaculicen la libertad de circulación de personas y bienes». La cuestión fundamental a dilucidar para abordar la interpretación del precepto es: ¿qué debe entenderse por obstáculo prohibido por la Constitución? Cuestión que se vincula con las dos interpretaciones que la doctrina (Quadra-Salcedo Janini, 2004) ha señalado que cabe realizar de aquellos preceptos que garantizan la libre circulación de persona y bienes en todo Estado descentralizado. Por un lado, la que entiende que tales preceptos deben ser interpretados como una garantía general del libre mercado frente a las regulaciones de los poderes públicos que restringen injustificadamente el libre acceso o el libre ejercicio de la actividad económica. Por otro lado, la que entiende que tales preceptos deben ser interpretados como una garantía de que las entidades territoriales no coloquen injustificadamente en una situación de ventaja a los bienes y a los operadores económicos locales frente a sus competidores de fuera. Es decir, con garantía frente al proteccionismo económico.

De aceptarse la primera interpretación, la función de los preceptos que garantizan la libre circulación de persona y bienes sería similar a la función que desempeñan los derechos fundamentales económicos, entre los que destacaría la libertad de empresa.

Sin embargo, en línea con la doctrina asumida en sistemas descentralizados clásicos de nuestro entorno, la reciente jurisprudencia constitucional ha acogido la segunda interpretación.

En efecto, cualquier normativa que, dentro de su ámbito competencial propio, establezca una comunidad autónoma puede incidir sobre los intercambios comerciales; sin embargo, no toda incidencia sobre aquellos es necesariamente un obstáculo prohibido por el art. $139.2 \mathrm{CE}^{24}$.

Las recientes SSTC 111/2017, de 5 de octubre, y 7/2018, de 25 de enero, han realizado una interpretación restringida del art. 139.2 CE al establecer que son únicamente los efectos restrictivos — de hecho o de derecho- injustificados

24 En este mismo sentido, señala Viver Pi Sunyer (1992: 51) que «todas las actuaciones de las Comunidades Autónomas, al establecer regímenes jurídicos propios y diferenciados de los existentes en el resto del territorio estatal, inciden en la circulación de personas y bienes». 
más onerosos sobre la circulación de bienes o personas provenientes de fuera de una comunidad autónoma que sobre los bienes o personas provenientes de dentro de una comunidad autónoma los que van a determinar que se considere una medida como prohibida bajo la perspectiva del art. $139.2 \mathrm{CE}^{25}$.

Así, la última doctrina constitucional ha diferenciado claramente entre la finalidad que tendría el art. 139.2 CE que recoge la garantía de la libre circulación de personas y bienes entre CC. AA. y la finalidad que tendría el art. $38 \mathrm{CE}$ que recoge la libertad de empresa.

La STC 111/2017 recuerda que el art. $38 \mathrm{CE}$ asegura a los individuos la libertad de intercambio comercial; esto es, la capacidad de ofrecer servicios o productos en el mercado, por lo que, en principio, restringiría tal libertad cualquier disposición susceptible de afectar al volumen general de los intercambios comerciales. La libertad de empresa es, no obstante, compatible con el establecimiento de restricciones y condiciones por parte de los poderes públicos con la finalidad de promover objetivos constitucionalmente legítimos; ahora bien, el art. 38 CE impone a su vez límites a la configuración legislativa de este tipo de restricciones y condiciones. En efecto, para el Tribunal Constitucional las condiciones o restricciones que se establezcan sobre el ejercicio de la actividad económica deben ajustarse a un canon de razonabilidad en el sentido de que respondan a un objetivo constitucionalmente legítimo y sean idóneas o adecuadas para conseguirlo sin que su intensidad llegue al punto de suponer un impedimento práctico del libre ejercicio de la actividad económica ${ }^{26}$.

25 El art. 139.2 CE prohibiría el establecimiento de regímenes diferenciados basados directamente en el origen de las personas o bienes, o aquellos que, sin basarse directamente en el origen de la persona o bien, tienen como efecto práctico el establecimiento de un régimen más oneroso sobre las personas o bienes provenientes de fuera de la comunidad que regula que sobre las personas o bienes de dentro. Así se sostiene en Quadra-Salcedo Janini (2008: 33 y ss.). Sin embargo, durante algunos ańos el Tribunal pareció realizar una interpretación amplia del concepto de obstaculizar al considerar vulneradoras de la libertad de circulación de personas y bienes las actuaciones autonómicas cuya incidencia sobre la libre circulación implicase el «surgimiento de obstáculos que no guarden relación y sean desproporcionados respecto del fin constitucionalmente lícito que persiguen" (SSTC 64/1990, de 5 de abril, FJ 5; 66/1991, de 22 de marzo, FJ 2; 233/1999, de 13 de diciembre, FJ 26; y 96/2002, de 25 de abril, FJ 11) y 168/2004, FJ 5). Tal interpretación habría sido abandonada en la STC $111 / 2017$, de 5 de octubre.

26 Para el Tribunal el canon ha de ser más incisivo si los requisitos o condiciones a la libertad de empresa afectan, no ya a su desarrollo o ejercicio, sino al acceso mismo al mercado (SSTC 53/2014, FJ 7; 30/2016, FJ 6, 35/2016, FJ 4 y 89/2017, FJ 14). En 
Tras haber caracterizado la libertad de empresa recogida en el art. $38 \mathrm{CE}$ como aquella que asegura a los individuos la libertad de intercambio comercial, la STC 111/2017 caracteriza la libre circulación de personas y bienes en todo el territorio espańol a la que se refiere el art. 139.2 CE como aquella que "proscribe las regulaciones o medidas de signo proteccionista; esto es, [las] que dificultan injustificadamente en un territorio la comercialización de productos de otras zonas o el ejercicio de actividades empresariales por parte de personas procedentes de otros lugares». Consecuentemente, bajo el prisma del art. 139.2 CE, cobra relevancia, afirma el Tribunal, «una única modalidad de límite o condición a la libertad empresarial: la que favorece a productos u operadores de un territorio en detrimento de los de otros lugares».

Así, cuando se adopta como canon de validez la libre circulación de personas y bienes del art. 139.2 CE solo serían susceptibles de caer bajo la prohibición del mismo aquellas medidas que tienen efectos, de hecho o de derecho, diferenciados. Una vez constatado ello, la STC 111/2017 recuerda que una restricción a la libre circulación de personas y bienes «será compatible con el art. 139.2 CE solo si la autoridad pública que la ha adoptado acredita que no persigue ni produce efectos discriminatorios, por responder a un objetivo constitucionalmente legítimo y ser idónea, necesaria y proporcionada $»^{27}$.

este punto hay que señalar una importante novedad jurisprudencial en relación con la interpretación de la Constitución económica que no será objeto de desarrollo en estas páginas, y es la que se refiere al surgimiento desde la STC 53/2014, de 10 de abril de una nueva doctrina del Tribunal Constitucional en la que se propugna la aplicación de un laxo escrutinio al controlar la constitucionalidad de aquellas regulaciones que afectan al ejercicio de las actividades económicas.

27 El escrutinio jurisdiccional al que se someten las regulaciones públicas bajo el art. 139.2 CE es, en principio, más estricto que el que se realiza bajo el art. $38 \mathrm{CE}$, tal como recuerda la STC 111/2017. En efecto, para determinar si un acto o disposición vulnera la libertad de empresa, el escrutinio al que se somete a las regulaciones públicas que afectan al ejercicio de tal libertad es de mera razonabilidad. Por el contrario, para determinar si un acto o disposición vulnera el art. 139.2 se debe emplear de acuerdo con la doctrina del Alto Tribunal un escrutinio de proporcionalidad. La razón para realizar un escrutinio distinto — razonabilidad (que comprendería la comprobación de la adecuación de la medida para promover el objetivo legítimo) en el caso del art. $38 \mathrm{CE}$ y proporcionalidad (que además de la adecuación comprendería la comprobación de la necesidad, esto es, de la inexistencia de alternativas menos restrictivas que promuevan igual de eficazmente el objetivo pretendido y en su caso la ponderación costes/beneficios) en el caso del art. 139.2 CE- es clara, mientras que la Constitución se muestra neutral en relación con el grado de intervención 
Así, para el Tribunal, «no contradice necesariamente el art. 139.2 CE toda medida que en la práctica produzca efectos restrictivos más onerosos sobre las cosas o personas provenientes de fuera»; únicamente lo hará «cuando persiga de forma intencionada la finalidad de obstaculizar la libre circulación o genere consecuencias objetivas que impliquen el surgimiento de obstáculos que no guarden relación y sean desproporcionados respecto del fin constitucionalmente lícito que pretenda la medida adoptada $\aleph^{28}$.

Así, desde las SSTC 111/2017 y 7/2018, y teniendo en cuenta la «topografía constitucional» y el derecho comparado, el art. 139.2 CE sería un precepto cuyo objetivo es garantizar la libre circulación de personas y bienes entre las CC. AA., lo cual se concreta en ser un precepto que prohíbe los «obstáculos al comercio interautonómico» injustificados y no en ser un precepto que prohíba los «obstáculos al comercio en general» injustificados. Evidentemente todo «obstáculo al comercio interautonómico» es susceptible de ser considerado un «obstáculo al comercio en general», pero no al contrario, no todo «obstáculo al comercio en general» es un «obstáculo al comercio interautonómico».

Para declarar que una medida de un poder público se encuentra proscrita por el art. 139.2 CE sería necesario, por tanto, que se cumplan dos condiciones: 1) que la medida obstaculice el comercio interautonómico, por tener efectos, de hecho o de derecho, diferenciados más onerosos sobre las personas o bienes provenientes de fuera que sobre las personas o bienes provenientes de dentro, no bastando con que obstaculice el comercio en general, y 2) que la medida no puede justificarse en la promoción proporcionada de un objetivo legítimo.

Del examen realizado de la interpretación jurisprudencial de los dos apartados del art. $139 \mathrm{CE}$ cabe concluir que si bien los mismos suponen un límite a lo que pueden hacer las CC. AA. al ejercer sus competencias, ninguno de los

pública en la economía, no se muestra neutral en relación con el hecho de que una entidad infraestatal promueva el proteccionismo económico.

La STC 89/2017, de 4 de julio, FJ 7, ha subrayado igualmente el diferente canon que se deriva del art. $38 \mathrm{CE}$ - un canon de razonabilidad a la hora de juzgar las regulaciones que afectan al ejercicio de la actividad económica-, y el que se deriva de la normativa básica estatal en vigor, fundamentalmente del art. 5 de la Ley 20/2013 _ un canon más incisivo de proporcionalidad a la hora de juzgar las regulaciones autonómicas que afectan al ejercicio de la actividad económica- Tal canon más incisivo no sería, sin embargo, una exigencia constitucional sino una exigencia legislativa y por tanto, en su caso, mudable.

28 STC $111 / 207$, FJ 4 a) 
dos preceptos es suficiente para garantizar los rasgos del mercado nacional único, pues no garantizan la igualdad, aun la básica, en las condiciones de ejercicio de la actividad económica en todo el territorio nacional.

\subsection{La libertad de empresa del art. 38 CE tampoco es una garantía de la igualdad en las condiciones básicas de ejercicio de la actividad económica en todo el territorio nacional}

La STC 109/2003, en línea con lo propuesto doctrinalmente en su día por Rubio Llorente ${ }^{29}$, consideró que las regulaciones públicas, para ser conformes con la libertad de empresa, deben cumplir como condición que las distintas empresas de un mismo sector se hallen sometidas al mismo género de limitaciones básicas en todo el territorio nacional, pues dicha libertad, se afirma, solo existe en una economía de mercado que resulta incompatible con posiciones jurídicas básicamente distintas de los diversos operadores ${ }^{30}$.

29 Sostiene Rubio Llorente (1993: 25 y ss.) que la libertad de empresa reconocida en el art. 38 conlleva, asociada con la idea de la unidad del mercado, la necesidad de que todas las empresas disfruten del mismo grado de libertad en razón de la clase a la que pertenecen, de manera que todas ellas sean jurídicamente iguales en el mercado nacional. En opinión de Rubio, ante la imposibilidad de fijar un contenido esencial propio de cada actividad empresarial, la conexión entre libertad e igualdad ofrece un punto de apoyo para establecer una noción de contenido esencial de la libertad de empresa: la intervención del poder público en esa libertad no puede ser tal que altere la igualdad de las empresas de una misma clase en el mercado nacional. Ello no significa que todas las empresas tengan el mismo grado de libertad, pero sí que esta sea igual para todas las que se dedican al mismo género de actividad. La concepción de Rubio significaría que la alteración de la igualdad entre las empresas situadas en las distintas partes del territorio nacional, que se puede derivar del ejercicio que las comunidades autónomas hagan de sus competencias normativas, podría suponer una vulneración del contenido esencial de la libertad de empresa. El contenido esencial de la libertad de empresa, bajo esta concepción, proscribiría la alteración de la igualdad de las empresas en el mercado nacional generada por la pluralidad regulatoria resultado del ejercicio de las competencias autonómicas.

30 La STC 109/2003 no hace sino desarrollar la idea recogida en la STC 96/2002, FJ 11, donde el Tribunal Constitucional afirmó que cabe «que la unidad de mercado se resienta a consecuencia de una actuación autonómica que, en ejercicio de competencias propias, obstaculice el tráfico de industrias. Así habrá de suceder cuando se provoque una modificación sustancial, geográfica o sectorial, del régimen de traslado en o para determinadas zonas del territorio nacional, se generen barreras financieras en 
La STC 96/2013 excluyó, sin embargo, que la existencia de una pluralidad de regulaciones que provocan que las condiciones de ejercicio de la libertad de empresa no sean las mismas en el mercado nacional vulnere por sí misma el contenido esencial de la libertad de empresa. Así, en efecto, el Tribunal en 2013 señaló que lo que se planteaba en el recurso de inconstitucionalidad interpuesto era si el sometimiento del ejercicio de una cierta actividad empresarial —en el caso la distribución comercial mediante grandes superficies- a distintas condiciones según el territorio donde se realizase ${ }^{31}$ vulneraba el derecho a la libertad de empresa del art. $38 \mathrm{CE}$ por el hecho de impedir que tal derecho se ejercitase en condiciones básicas de igualdad. La STC 96/2013 considera que una regulación autonómica que introduzca un régimen diverso del o de los existentes en el resto de la nación es admisible con tal de que dentro del ámbito competencial respectivo resulte proporcionada al objeto legítimo que se persigue.

Si en la STC 109/2003 la garantía de la igualdad en las condiciones de ejercicio en todo el territorio nacional se constituía en un límite absoluto frente al legislador, en la STC 96/2013 es la desigualdad en tales condiciones la que determina la necesidad de aplicar un escrutinio estricto de proporcionalidad a aquellas medidas de los poderes públicos que la generan. La igualdad en las condiciones de ejercicio deja así de pertenecer al contenido esencial del derecho como contenido indisponible, pero se constituye en el presupuesto para someter la medida a un escrutinio de proporcionalidad.

Las SSTC 53/2014, FJ 7; 30/2016, FJ 6; y 89/2017, FJ 15, han revocado claramente la doctrina que considera que las regulaciones públicas, para ser conformes con la libertad de empresa, deben cumplir como condición que las

torno a alguna de ellas o se desvirtúen artificialmente con el concurso de factores externos al mercado, la igualdad de medios y posibilidades de desplazamiento de las industrias que concurren en el mismo espacio económico. Y ello no sólo a través de medidas coactivas que directamente impongan trabas injustificadas a la circulación de industrias o a su desarrollo en condiciones básicas de igualdad, sino también mediante medidas de naturaleza graciable y acogimiento voluntario como ayudas, subvenciones u otro tipo de auxilios, que, en el marco de la actual Administración prestacional, adquieren, junto a su tradicional configuración como medios de fomento, promoción y protección empresarial, una innegable virtualidad de instrumentos de intervención económica, de los que puede llegar a hacerse un uso incompatible con las exigencias del mercado único, por propiciar, en mayor o menor grado, la disociación en ciertas zonas o sectores de reglas económicas que han de permanecer uniformes».

31 Concretamente, a un diferente régimen impositivo dependiendo de si se desenvuelve la actividad en la comunidad autónoma que ha establecido el impuesto o en otra. 
distintas empresas de un mismo sector se hallen sometidas al mismo género de limitaciones básicas en todo el territorio nacional.

Ciertamente, la libertad de empresa reconocida en el art. 38, garantiza —además de la adecuación de las restricciones públicas al ejercicio de la actividad económica a la promoción de un objetivo constitucionalmente legítimo $^{32}$ - la igualdad de limitaciones de la actividad económica para las empresas de una misma clase, pero tal exigencia de igualdad se produce, de acuerdo con la jurisprudencia constitucional, ante cada ordenamiento individualmente considerado, el estatal y los autonómicos ${ }^{33}$.

Señala la STC 89/2017 que

en efecto, la potencial diversidad en las condiciones de ejercicio de la libertad de empresa en las diferentes partes del territorio nacional derivada del ejercicio por las CCAA de sus propias competencias no constituye una vulneración del contenido esencial de la libertad de empresa, pues tal y como ha señalado la jurisprudencia «la potestad legislativa de que las Comunidades Autónomas gozan potencialmente da a nuestro ordenamiento una estructura compuesta, por obra de la cual puede ser distinta la posición jurídica de los ciudadanos en las distintas partes del territorio nacional» (STC 37/1981, de 16 de noviembre, FJ 2). Así, el derecho a desarrollar una actividad empresarial en condiciones de igualdad que es, indudablemente, una manifestación de la libertad de empresa, se impone, como ha declarado el Tribunal, ante cada ordenamiento, estatal o autonómico, individualmente considerado y no es posible considerar que del referido derecho se deriva la exigencia de que las concretas condiciones de ejercicio de la actividad económica tengan que ser las mismas en todo el territorio nacional (FJ 15).

No obstante lo anterior, el Tribunal subraya que «corresponde [...] a los órganos centrales del Estado la eventual decisión de fijar aquellas condiciones básicas que garanticen la igualdad de los españoles en el ejercicio de los derechos y en el cumplimiento de los deberes constitucionales a través, en su caso, del efectivo ejercicio de la competencia que le reconoce el artículo 149.1.1 CE». Apelación, esta última, que va en la línea de la referencia a las garantías dinámicas del mercado único que realiza la STC 79/2017.

32 Lo cual supone revocar igualmente la doctrina establecida en la STC 96/2013, en relación con que es la desigualdad en las condiciones de ejercicio en las diferentes partes del territorio nacional la que determina la necesidad de aplicar un escrutinio estricto de proporcionalidad a aquellas medidas de los poderes públicos que la generan.

33 SSTC 53/2014, FJ 7, y 30/2016, FJ 6. 


\subsection{La competencia recogida en el art. 149.1.1 CE no es, por sí misma, un límite al ejercicio competencial autonómico}

En la jurisprudencia del Tribunal de los primeros años ochenta se consideró el art. 149.1.1 CE como un límite a las competencias autonómicas.

Así, en efecto, para el Tribunal Constitucional mientras una «norma legal (autonómica), aunque con incidencia sobre el ejercicio de derechos, no afecte a las condiciones básicas de tal ejercicio, puede ser promulgada por las Comunidades Autónomas cuyos Estatutos le atribuyan competencia legislativa sobre una materia cuya regulación implique necesariamente, en uno u otro grado, una regulación del ejercicio de derechos constitucionalmente garantizados» ${ }^{34}$. Lo que supone considerar que el legislador autonómico puede regular el ejercicio de los derechos y libertades en el ámbito de sus competencias, pero siempre que no afecte a las condiciones básicas de tal ejercicio. Entre tales derechos y libertades constitucionales se incluirían aquellos más directamente vinculados con la conformación de un mercado único como sería el derecho a la libertad de empresa del art. $38 \mathrm{CE}$, cuyas condiciones básicas, según esta primera interpretación jurisprudencial, no podrían verse afectadas por la acción de las CC. AA.

Sin embargo, la concepción del art. 149.1.1 CE como un precepto en sí mismo limitador de la acción legislativa de las CC. AA. parecerá abandonarse en una jurisprudencia posterior de finales de los noventa que desde entonces viene negando al art. 149.1.1 CE el carácter de límite directo a la acción legislativa de las CC. $\mathrm{AA}^{35}$.

En efecto, el Tribunal, en su STC 61/1997, de 20 de marzo, tras considerar que el art. 149.1.1 CE es un título competencial autónomo del Estado, declarará que «el art. 149.1.1 CE no debe ser entendido como una prohibición de divergencia autonómica»" ${ }^{36}$.

En efecto, en la STC 173/1998, de 23 de julio, el Tribunal afirmará que

en tanto que [una] legislación estatal no se haya dictado, resultará sumamente difícil atribuir a la legislación autonómica una invasión competencial, ya que el artículo 149.1.1 CE, más que delimitar un ámbito material excluyente de toda intervención de las Comunidades Autónomas, lo que contiene es una habilitación para que el Estado condicione —-mediante, precisamente, el establecimiento de

\footnotetext{
34 STC 37/1981, FJ 2. Cursiva nuestra.

35 Únicamente en relación con la potestad sancionadora se continuará afirmando por la jurisprudencia del Tribunal la existencia de límites a las comunidades autónomas derivados del art. 149.1.1 CE.

36 STC 61/1997, de 20 de marzo. FJ 7 b).
} 
unas «condiciones básicas» uniformes - el ejercicio de esas competencias autonómicas con el objeto de garantizar la igualdad de todos los españoles en el ejercicio de sus derechos y en el cumplimiento de sus deberes constitucionales. En suma, si el Estado considera necesario establecer en el futuro esas condiciones básicas y al dictarlas éstas entraran en contradicción con preceptos de leyes autonómicas en vigor, estos últimos quedarían automáticamente desplazados por aquellas ${ }^{37}$.

Descartado por la jurisprudencia el carácter de límite directo al art. 149.1.1 CE, para que el Tribunal pueda realizar un juicio de constitucionalidad en relación con la vulneración de aquel precepto será menester que la representación de los recurrentes de una norma autonómica aporte los preceptos legales concretos de la normativa estatal que a su juicio contendrían las condiciones básicas que garantizarían la igualdad de los españoles en el ejercicio de los derechos constitucionales.

Esta doctrina supone aceptar que en ausencia de ejercicio por el Estado de la competencia reservada en el art. 149.1.1 CE, el ejercicio por la comunidad autónoma de sus competencias materiales no se ve sometida a límite alguno derivado de tal reserva y solo en el supuesto de un ejercicio efectivo por el Estado de su competencia transversal se producirá el desplazamiento de las regulaciones autonómicas que se le opongan y que mientras tanto son plenamente aplicables por haber sido dictadas en ejercicio de competencias materiales propias.

En parecidos términos debe interpretarse la competencia prevista en el art. 149.1.13 CE, que se ha considerado por la doctrina constitucional una competencia sobre la ordenación general de la actividad económica y que viene permitiendo al Estado regular materias estatutariamente reservadas a las CC. AA. con la finalidad de establecer los rasgos del mercado único, sin que en ausencia de su ejercicio quepa extraer límite alguno de la habilitación que tal competencia supone.

Tal interpretación implica reconocer que uno de los rasgos esenciales de un mercado nacional único, la igualdad de condiciones de ejercicio de la actividad económica en el territorio nacional, no se encontraría impuesto ni por el art. 149.1.1 CE ni por el art. 149.1.13 CE, si bien, tal como ha afirmado la STC 79/2017, la ausencia de tales condiciones básicas sería precisamente el presupuesto que permitiría al Estado, en su caso, ejercer sus competencias normativas para promover tal rasgo del mercado único ${ }^{38}$.

37 STC 173/1998, de 23 de julio, FJ 9.

38 En el mismo sentido, la STC 89/2017 recuerda que si bien del reconocimiento constitucional del derecho a la libertad de empresa «no es posible considerar que [...] se 


\section{EL ALCANCE DE LAS DENOMINADAS GARANTÍAS DINÁMICAS DEL MERCADO ÚNICO}

La STC 79/2017, considera que las denominadas garantías estructurales, aquellas que suponen un límite en sí, un límite directo desde la Constitución, a la diversidad regulatoria que puedan introducir los legisladores autonómicos pueden no ser suficientes para imponer los rasgos del mercado único. Es por ello por lo que considera que la Constitución ha previsto las denominadas garantías dinámicas del mercado único, que estarían constituidas por los títulos competenciales horizontales reservados al Estado fundamentalmente en los apdos. 1 (sobre regulación de la condiciones básicas que garantizan la igualdad de todos los españoles en el ejercicio de los derechos y en el cumplimiento de los deberes) y 13 (sobre bases y coordinación de la planificación general de la actividad económica) del art. 149.1 CE, y que permitirían a este intervenir normativamente cuando las "garantías estructurales» se demuestran insuficientes para imponer aquellos rasgos ${ }^{39}$.

La doctrina del Tribunal Constitucional de los últimos años viene realizando una amplia interpretación del alcance de los títulos competenciales horizontales referidos ${ }^{40}$.

deriva la exigencia de que las concretas condiciones de ejercicio de la actividad económica tengan que ser las mismas en todo el territorio nacional. Corresponde, no obstante, a los órganos centrales del Estado la eventual decisión de fijar aquellas condiciones básicas que garanticen la igualdad de los españoles en el ejercicio de los derechos y en el cumplimiento de los deberes constitucionales a través, en su caso, del efectivo ejercicio de la competencia que le reconoce el artículo 149.1.1CE» (FJ 15).

39 Afirma el Tribunal que «aquella unidad puede igualmente promoverse a través de un ejercicio efectivo por el Estado de aquellas competencias horizontales que nuestra norma fundamental le ha reconocido (por ejemplo en los apartados 1 y 13 del art. 149.1 CE). En este sentido es posible diferenciar entre unas garantías estructurales y unas garantías dinámicas de la unidad económica. Las primeras se vincularían con el hecho de que todos los poderes públicos deban respetar en su actuación aquellas competencias y aquellos principios constitucionales que, al suponer un límite en sí a la diversidad regulatoria, preservan, en alguna medida, los rasgos propios del mercado nacional único. Las segundas permitirían al Estado promover, en su caso, tal unidad — cuando las primeras "se demuestran insuficientes" para garantizarla (SSTC 96/2013, de 23 de abril, FJ 4 y 20/2016, de 4 de febrero, FJ 3)—, a través de la decisión de ejercer sus competencias transversales» (FJ 2).

40 Sobre la amplia interpretación realizada del apdo. 13 del art. 149.1 véase Carrasco Durán (2005), interpretación que con posterioridad ha ido incluso más lejos que la que se refleja en el referido estudio. En relación con la interpretación del apdo. 1 del 
Ciertamente, las garantías dinámicas no habilitan al Estado para regular de cualquier manera con la finalidad de evitar la fragmentación del mercado, pues la propia STC 79/2017, declara la inconstitucionalidad y nulidad del principio de eficacia ${ }^{41}$ recogido en la Ley 20/2013 de Garantía de la Unidad de Mercado ${ }^{42}$.

Pero el Tribunal no se conforma con declarar la nulidad de la concreta respuesta que ha dado el legislador estatal a la existencia de una pluralidad regulatoria que puede poner en cuestión los rasgos del mercado único, el principio de eficacia nacional ${ }^{43}$, por vulnerar el principio de territorialidad, sino

art. 149.1 baste señalar la STC 33/2014, de 27 de febrero, en la que el Tribunal considera "posible promover, a través de la competencia reconocida al Estado en el art. 149.1.1 CE que los principios rectores de la política social y económica del capítulo III del título I de la Constitución pueden ponerse en conexión directa con la regla competencial ex art. 149.1.1 CE» (FJ 4).

41 El establecimiento por parte del legislador estatal en la Ley 20/2013 de un principio de eficacia incondicionada de los actos y disposiciones de los poderes públicos autonómicos de origen en todo el territorio nacional genera que en un determinado territorio autonómico, el de destino, las autoridades del mismo, como autoridades de destino, tengan que reconocer una pluralidad de regímenes jurídicos de derechos y deberes en función del origen del operador económico o del producto.

42 Para el Tribunal Constitucional el otorgamiento a través del denominado principio de eficacia nacional de eficacia extraterritorial a las disposiciones autonómicas que establecen un estándar distinto al estándar que fija la normativa autonómica del lugar de destino supone la ruptura del principio de territorialidad constitucionalmente consagrado y estatutariamente reconocido y supone obligar a una comunidad autónoma a tener que aceptar dentro de su territorio una pluralidad de políticas ajenas. Aceptación que choca con la capacidad para elaborar sus propias políticas públicas en las materias de su competencia y entrańa la constricción de su autonomía al permitirse la aplicación en el territorio de la comunidad autónoma de disposiciones adoptadas por un órgano representativo en el que los ciudadanos de la comunidad autónoma en la que finalmente se aplica no se encuentran representados. Así, en efecto, cabe deducir de la STC 79/2017 que la configuración del principio de eficacia nacional que realiza la Ley 20/2013 olvida que la territorialidad no solo responde a la necesidad de hacer compatible el ejercicio simultáneo de las competencias asumidas por las distintas comunidades, sino que además permite preservar alguna de las dimensiones más relevantes del principio democrático, pues la territorialidad supone el establecimiento de un criterio claro de imputación de responsabilidades desde la perspectiva de la rendición de cuentas.

43 Principio, el de eficacia nacional, que en realidad no promueve los rasgos del mercado único, pues consiente la existencia de una pluralidad de regulaciones, las de origen y las de destino, que conllevan que no exista una igualdad de condiciones en el 
que se refiere a otras potenciales respuestas que, con la misma finalidad, atenuar la pluralidad, sí serían, sin embargo, constitucionales por ser conformes con la interpretación de los mecanismos de promoción del mercado nacional único a los que se había referido el Tribunal Constitucional en el ya examinado FJ 2.

Así, el Tribunal afirma la constitucionalidad del denominado reconocimiento mutuo condicionado a la equivalencia en el nivel de protección, pues el presupuesto para que sea considerado constitucional un eventual principio de eficacia nacional es precisamente la existencia de tal equivalencia. Para el Tribunal, en la medida en que exista una normativa de la Unión Europea armonizada, una legislación estatal común, o exista una pluralidad de legislaciones autonómicas que, no obstante sus posibles diferencias técnicas o metodológicas, fijen un estándar que pueda ser considerado equivalente, el Estado podrá reconocer a las decisiones autonómicas efectos extraterritoriales a través de la imposición del reconocimiento de la decisión adoptada en una determinada comunidad autónoma en el resto. El principio de reconocimiento mutuo puede consentir la eficacia extraterritorial de los actos y disposiciones de un determinado poder territorial; pero, en ausencia de uniformización del nivel de protección, deja subsistente la capacidad de los poderes territoriales de establecer, un nivel de protección propio y distinto.

Así, para mitigar algunas de las consecuencias de la existencia de una pluralidad regulatoria fundada en la legítima capacidad territorial de adoptar políticas propias, la STC 79/2017 considera que cabe acudir a la elaboración de una estrategia normativa consistente en el establecimiento de un estándar común a través del ejercicio por parte del poder central de sus competencias horizontales (apdos. 1 y 13 del art. 149.1 CE). El Estado, para promover la unidad de mercado, puede en ejercicio de sus competencias transversales crear un marco normativo unitario de aplicación a todo el territorio nacional.

El Tribunal, en línea con sistemas políticos descentralizados de nuestro entorno $^{44}$, admite así una amplia capacidad al Estado para promover los ras-

ejercicio de la actividad económica. Así, en efecto, el principio de eficacia es un instrumento de desregulación del espacio económico y ciertamente consigue suprimir los obstáculos a la libre circulación pero lo hace sin garantizar la igualdad de condiciones de ejercicio de la actividad económica.

44 Como el norteamericano, en el que se ha dado una amplia interpretación a la denominada cláusula de comercio positiva (Quadra-Salcedo Janini, 2004) o el de la Unión Europea, donde se ha dado una amplia interpretación a las competencias para garantizar y promover el establecimiento y el funcionamiento del mercado interior (Quadra-Salcedo Janini, 2006). 
gos del mercado único, pues en estos casos el único límite es que las CC.AA. dispongan de «un margen de actuación que les permita establecer los elementos complementarios» del marco normativo unitario que establezca el Estado. Lejos queda la apelación a la necesidad de garantizar la capacidad autonómica de promover políticas propias como ámbito que debe ser respetado por el Estado al ejercer la competencia del art. 149.1.13 CE, pues cuando se trata de promover los rasgos del mercado único el margen autonómico a respetar que se deduce de la STC 79/2017 es más reducido, únicamente se exige que dentro del eventual marco normativo unitario que fije el Estado, se permita a las CC. AA. establecer los elementos complementarios a aquel marco pero sin poder apartarse del mismo ${ }^{45}$.

Así, de la doctrina del Tribunal Constitucional se desprende que la norma fundamental no ha asegurado los rasgos del mercado nacional único a través de su garantía directa — vía garantías estructurales de la unidad-, pero sí ha previsto que aquellos puedan ser promovidos a través de la acción normativa estatal — vía garantías dinámicas-.

\section{A MODO DE CONCLUSIÓN}

La construcción doctrinal examinada supone llevar en buena medida la discusión relativa al grado de unidad y al grado de descentralización de nuestro mercado nacional a la arena política; y supone aceptar que en materia de construcción de la unidad de mercado, el reconocimiento estatutario de determinadas competencias materiales a las CC. AA. no puede suponer, como regla general, un obstáculo insalvable a la capacidad estatal de eventualmente promover la unidad incluso a costa de regular ámbitos materiales reservados estatutariamente a aquellas a través del ejercicio de sus competencias horizontales.

Ciertamente, ello supone, como ocurre también en otros sistemas descentralizados, la relativización de la capacidad de decisión de las entidades regionales como consecuencia de la proyección o reflejo que sobre sus competencias pueda tener el eventual ejercicio efectivo de los títulos competenciales horizontales estatales.

45 La Ley 20/2013 habría acudido a un instrumento distinto de los referidos al establecer el denominado principio de eficacia nacional de las disposiciones y actos autonómicos. Distinto, pues no supone ni el establecimiento de un principio de reconocimiento mutuo condicionado a la equivalencia en el nivel de protección ni el establecimiento de un marco normativo uniforme de aplicación a todo el territorio nacional y por ello es declarado inconstitucional. 
Frente al riesgo de vaciamiento o afectación de la capacidad de decisión territorial como consecuencia de la capacidad central de promover en un momento dado de manera más incisiva los rasgos del mercado único, cabe plantear la necesidad de potenciar la participación de los representantes de las CC. AA. en los órganos estatales encargados de ejercer tales competencias horizontales ${ }^{46}$.

Ciertamente, las referidas garantías políticas no son alternativas o excluyentes de las garantías jurídicas, son complementarias, pero aquellas se demuestran como más efectivas que estas en los actuales Estados compuestos — donde se ha atribuido al poder central una amplia capacidad de decisión con la finalidad de garantizar la igualdad y la unidad - como mecanismo para garantizar un ámbito propio de decisión territorial considerado suficiente por los propios niveles territoriales.

Pero igualmente cabría señalar que es en otros ámbitos distintos al de la eventual construcción de un mercado unitario, como es el relativo al ámbito de desarrollo del Estado social prestacional, en el que cabría considerar la existencia de una verdadera capacidad autonómica de desarrollar políticas propias de mejora de un eventual mínimo estatal (Quadra-SalcedoJanini, 2017). Ello supondría considerar que nuestro Estado autonómico, a pesar de poseer importantes instrumentos que permiten promover la unidad en el ámbito económico, al tiempo otorga un margen experimental de desarrollo a partir del mínimo establecido por el poder central en el ámbito social prestacional. En efecto, si en lo que se refiere a la conformación de los rasgos del mercado nacional único la potencial uniformidad decidida por el poder central se constituye en un límite que se puede imponer a la diversidad normativa, pues el interés general reflejado en la existencia de un mercado único se contrapone al interés autonómico reflejado en la posibilidad de desarrollar políticas propias, en el ámbito de la determinación del nivel de prestaciones sociales no se produce una verdadera contraposición entre el «interés autonómico» y el «interés general» (estatal), pues en una materia como es la relativa a las medidas públicas de acción y protección social no puede darse una colisión de intereses, que siempre serán coincidentes como consecuencia del mandato constitucional de promoción de los derechos sociales.

46 La pérdida de capacidad de decisión de las comunidades autónomas quedaría relativizada si existiese un Senado como verdadera Cámara de representación territorial con la función de dar cauce de participación a los intereses autonómicos en la elaboración de determinadas leyes del Estado; Aja y Arbós (1980). En el mismo sentido de posibilitar la participación de las CC. AA. en el ejercicio de las competencias del Estado se pronunció tempranamente Cruz Villalón (1981: 61). 


\section{Bibliografía}

Aja, E. (1992). El artículo 149.1.1 de la Constitución como Cláusula de cierre del principio de igualdad social. En La función del artículo 149.1.1 de la CE en el sistema de distribución de competencias (Seminario celebrado en Barcelona el 7 de junio de 1991). Barcelona: IEA.

Aja, E. y Arbós i Marín, X. (1980). El Senado, cámara posible de las autonomías. Revista de Estudios Politicos, 17, 27-66.

Albertí Rovira, E. (1995). Autonomía Politica y Unidad Económica. Madrid: Civitas.

- (2008). La igualdad de derechos y la libre circulación en el Estado Autonómico. En Comentarios a la Constitución Española. Madrid: Fundación Wolters Kluwer.

Alonso Más, M. J. (2014). Reflexiones sobre la Ley de Garantía de la Unidad de Mercado. Derecho de los Negocios, 25 (273), 1.

Aragón Reyes, M. (2008). Prólogo. En T. de la Quadra-Salcedo Janini. Mercado nacional Único y Constitución. Madrid: Centro de Estudios Políticos y Constitucionales.

Cabellos Espierrez, M. A. (2001). Distribución competencial, derechos de los ciudadanos e incidencia del derecho comunitario. Madrid: Centro de Estudios Políticos y Constitucionales.

Cámara Villar, G. (2007). En F. Balaguer (coord.). El nuevo Estatuto de Andalucía. Madrid: Tecnos.

Carlón Ruiz, M. (2014). Los mecanismos de protección de la Ley de unidad de mercado en el seno de la Ley 20/2013. Revista Española de Derecho Administrativo, 165, 147-182.

Carrasco Durán, M. (2005). El reparto de competencias entre el Estado y las Comunidades Autónomas sobre la actividad económica. Valencia: Tirant Lo Blanch.

Cidoncha Martín, A. (2015). Sobre la Ley de Garantía de la Unidad de Mercado: una reflexión jurídico-constitucional. CEF Legal: revista práctica de derecho. Comentarios y casos prácticos, 179, 105-140.

Cosculluela Montaner, L. (2003). Reflexiones sobre los presupuestos constitucionales y de derecho comunitario europeo y los principios generales del derecho público económico. En Estudios de Derecho Público Económico. Libro Homenaje al prof. Dr. D. Sebastián Martín-Retortillo. Madrid: Civitas.

Cruz Villalón, P. (1981), La estructura del Estado, o la curiosidad del jurista persa. Revista de la Facultad de Derecho de la Universidad Complutense, 4 (1987), 1918-1939.

De Otto y Pardo, I. (1986). Estudios sobre Derecho estatal y autonómico. Madrid: Civitas.

Fernández Farreres, G. (2014). Unidad de mercado y libertades de empresa y de circulación de bienes en la ley 20/2013, de 9 de diciembre. Revista Española de Derecho Administrativo, 163, 109-144.

López Guerra, L. (1990). Consideraciones sobre la regulación de las condiciones básicas del artículo 149.1.1. En A. Pérez Calvo (coord.). Normativa básica en el ordenamiento juridico español. Madrid: MAP.

Marx, F (1976). Funktion und Grenzen der Rechtsangleichung nach Art. 100 EWG-Vertrag. Heymann, 1976.

Muñoz Machado, S. (2014). Sobre el restablecimiento legal de la unidad de mercado. Revista Española de Derecho Administrativo, 163, 11-22. 
Narbón Fernández, J. (2016). Los discutibles presupuestos económicos de la Ley de garantía de la unidad de mercado. Revista Española de Derecho Administrativo, 175, 161-194.

Padros Reig, C. y Macias Castaño, J. M. (2014). Los instrumentos administrativos de garantía de la unidad de mercado. Revista de Administración Pública, 194, 113-151.

Quadra-Salcedo Janini, T. (2004). Unidad económica y descentralización politica. Libre circulación de mercancías y control judicial en EE. UU. y en la Unión Europea. Valencia: Tirant Lo Blanch.

- (2006). El sistema europeo de distribución de competencias. Madrid: Civitas.

- (2008). Mercado nacional único y Constitución. Madrid: Centro de Estudios Políticos y Constitucionales.

- (2009). El derecho de residencia como derecho a tener derechos en los sistemas políticos compuestos. Revista Española de Derecho Constitucional, 29 (87), 109-154.

- (2017). Estado autonómico social. El efecto de irradiación de los derechos sociales sobre el modelo constitucional de distribución de competencias. Revista General de Derecho Administrativo, 46.

Rebollo Puig, M. (2015). La Ley de garantía de la unidad de mercado. En especial, los principios de necesidad y de eficacia nacional y su repercusión sobre las Comunidades Autónomas. En Informe de Comunidades Autónomas 2014.

Ruiz-Rico Ruiz, G. (2001). Los límites constitucionales del Estado Autonómico. Madrid: Centro de Estudios Políticos y Constitucionales.

Rubio Llorente, F. (1993). La libertad de empresa en la Constitución. En E. Borrajo (ed.). La reforma del mercado de trabajo. Madrid: Actualidad Editorial.

Solozábal Echavarría, J. J. (1998). Bases constitucionales del Estado autonómico. Madrid: McGraw-Hill.

Urrutia Libarona, I. (2016). La configuración legal de la unidad de mercado y estado autonómico. Revista Española de Derecho Administrativo, 175, 195-236.

Viver Pi Sunyer, C. (1992). La libertad de circulación y de establecimiento de las personas y la libertad de circulación de bienes (art. 139.2 CE). En La función del artículo 149.1.1 de la CE en el sistema de distribución de competencias: Seminario celebrado en Barcelona el 7 de junio de 1991. IEA. 